\title{
ANALISIS KETEPATAN FREKUENSI PEMBANGKIT CLOCK BERBASIS MIKROKONTROLER
}

\author{
Freedy Kurniawan \\ Jurusan Teknik Elektro, Sekolah Tinggi Teknologi Adisutjipto \\ Jl. Janti Blok R, Kompleks Lanud Adisutjipto, Yogyakarta \\ Telepon: (0274) 451262 Eks 110; Faksimil: (0274) 451265 \\ e-mail: freddykurniawan@yahoo.com
}

\begin{abstract}
Many electronics experience require clock generator. In common, analog clock generator able to generate clock signal with 5\% error, and digital clock generator can generate with $0.1 \%$ error. Microcontroller-based clock signal generator has crystal accuracy. The useful frequency range that can be generated is between $1 \mathrm{~Hz}$ and $1 \mathrm{MHz}$ when the microcontroller operating at a $24 \mathrm{MHz}$ clock frequency. A $1 \mathrm{MHz}$ frequency output can be generated by execute continuously a one-cycle-instruction to complement the pin output. To generate a specific frequency below $1 \mathrm{MHz}$, the other instruction(s) such as nooperation can be inserted to delay the next instruction.
\end{abstract}

Kata kunci: pembangkit clock, mikrokontroler, galat.

\section{PENDAHULUAN}

Sebuah mikrokontroler mempunyai beberapa port keluaran. Dari port tersebut dapat dikeluarkan isyarat clock dengan frekuensi tertentu. Aras rendah clock dapat dikeluarkan dengan memberikan logika rendah pada keluaran port tersebut; dan aras tinggi clock dapat dikeluarkan dengan memberikan logika tinggi pada keluaran port tersebut. Frekuensi tertinggi clock yang dapat dikeluarkan sebuah port tergantung pada frekuensi clock yang diberikan kepada mikrokontoler tersebut dan pemilihan instruksi yang tepat.

\section{PEMBANGKIT ISYARAT CLOCK}

Pembangkitan isyarat clock dapat dilakukan minimal dengan tiga cara. Pertama, dengan mengeluarkan data logika tinggi diikuti dengan data logika rendah secara periodis. Hal ini dapat dilakukan dengan instruksi pemindahan data seperti MOV. Agar dapat diperoleh frekuensi clock cukup tinggi, maka dipilih instruksi yang mempunyai waktu eksekusi paling kecil yaitu satu siklus. Contoh instruksi tersebut adalah MOV P1, A (Atmel Corp., 1997). Jika suatu mikrokontroler dioperasikan dengan clock $24 \mathrm{MHz}$, maka dengan instruksi tersebut perubahan logika keluaran port 1 dapat dilakukan setiap 0,5 mikrodetik sekali.
Cara kedua dengan mengeset dan mereset sebuah pin port keluaran. Hal ini dapat dilakukan dengan instruksi SETB $<$ pin_port> dan CLR <pin_port>. Cara kedua ini mempunyai kelebihan tidak terlibatnya data di memori lain. Sedangkan cara ketiga adalah dengan menegasikan logika port keluaran. Dengan menggunakan instruksi CPL <pin_port>, maka logika keluaran di suatu pin pada port keluaran dapat dinegasikan setiap satu siklus sekali atau 0,5 mikrodetik sekali.

\section{Pembangkit Clock $1 \mathrm{MHz}$}

Dengan mengoperasikan mikrokontroler pada frekuensi $24 \mathrm{MHz}$, maka satu siklus bahasa mesin yang terdiri dari enam fase dapat dieksekusi dalam waktu 0,5 mikrodetik (Atmel Corp., 2007). Dengan menggunakan instruksi CPL P1.0 berturut-turut, maka di pin 0 port 1 akan diperoleh keluaran isyarat clock dengan periode 1 mikrodetik atau berfrekuensi $1 \mathrm{MHz}$.

Keluaran pin 0 port 1 diharapkan berbentuk gelombang kotak dengan frekuensi $1 \mathrm{MHz}$. Namun dengan adanya efek kapasitif pada keluaran port tersebut, bentuk gelombang berbentuk keluaran mungkin tidak kotak, tapi mendekati keluaran gelombang kotak yang telah melalui untai integrator. Untuk mengembalikan bentuk tersebut ke gelombang kotak dapat digunakan gerbang dengan pemicu Schmitt, misalnya gerbang NOT dengan pemicu Schmitt 74LS14 (Tocci dan Widmer, 1998). 


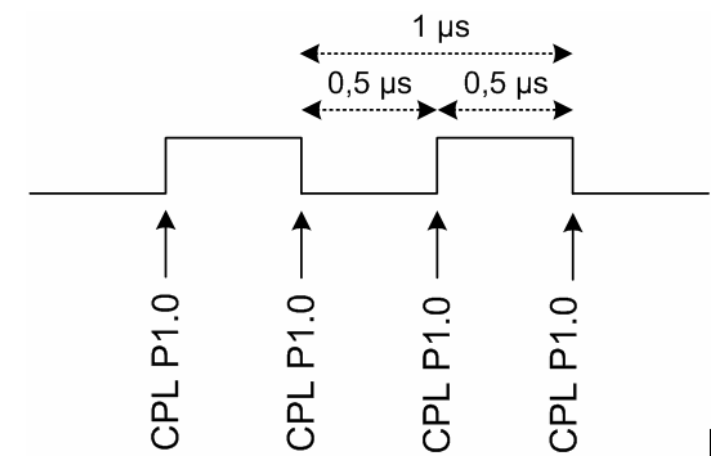

Gambar 1. Pembangkitan clock $1 \mathrm{MHz}$ di port 1 pin 0.

\section{Pembangkit Clock kurang dari $1 \mathrm{MHz}$}

Clock dengan frekuensi kurang dari $1 \mathrm{MHz}$ dapat dibentuk dengan menunda pelaksanaan instruksi CPL P1.0 berikutnya. Penundaan dapat dilakukan dengan menyisipkan instruksi untuk tidak mengerjakan apa-apa, yaitu NOP (No operation). Instruksi tersebut membutuhkan waktu eksekusi satu siklus. Penyisipan satu instruksi NOP di antara dua instruksi CPL P1.0 akan menunda eksekusi instruksi CPL P1.0 berikutnya selama satu siklus. Dengan mengoperasikan mikrokontroler ini pada clock $24 \mathrm{MHz}$, maka instruksi CPL berikutnya akan tertunda satu siklus atau 0,5 mikrodetik, sehingga selang eksekusi dua instruksi CPL adalah $1 \mu \mathrm{s}$.

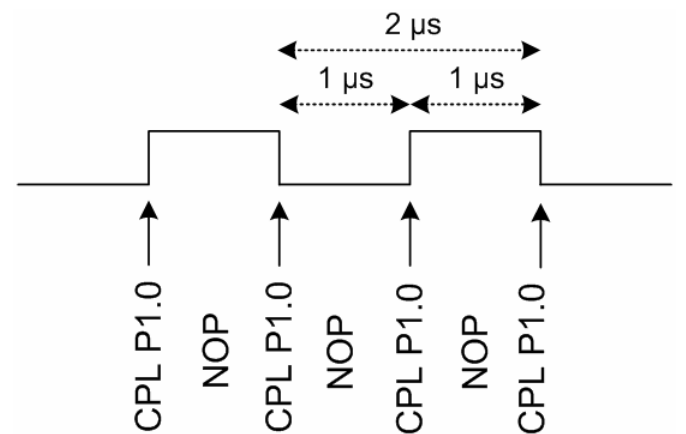

Gambar 2. Pembangkitan frekuensi clock 500 kHz

Penyisipan satu instruksi NOP akan membentuk clock dengan periode 2 mikrodetik atau berfrekuensi $500 \mathrm{kHz}$. Penyisipan tiga instruksi NOP akan membentuk clock dengan frekuensi $333.333 \mathrm{~Hz}$. Jumlah instruksi NOP yang dapat disisipkan dan frekuensi clock keluaran dapat dilihat pada Tabel 1.

Tabel 1. Jumlah instruksi NOP yang disisipkan dan frekuensi clock keluaran

\begin{tabular}{|c|c|c|c|c|c|c|c|c|c|}
\hline $\begin{array}{c}\text { NOP yang } \\
\text { disisipkan }\end{array}$ & 1 & 2 & 3 & 4 & 5 & 6 & 7 & 8 & 9 \\
\hline$f_{\text {clock }}(\mathrm{kHz})$ & 500 & 333 & 250 & 200 & 167 & 143 & 125 & 111 & 100 \\
\hline
\end{tabular}

Penyisipan instruksi NOP dengan jumlah melebihi 10 menjadikan listing program menjadi panjang. Untuk itu dapat digunakan listing penundaan yang menggunakan struktur perulangan, misalnya dengan instruksi DJNZ atau CJNE.

$$
\begin{gathered}
\text { MOV } R_{n}, \# \text { data } \\
\text { Ulang: } \\
\text { DJNZ } R_{n}, \text { Ulang }
\end{gathered}
$$

Baris pertama listing di atas mempunyai waktu eksekusi 1 siklus, sedangkan baris kedua mempunyai waktu eksekusi 2 siklus. Dengan mengakurasikan nilai \#data dengan waktu tundaan, instruksi tundaan dengan perulangan seperti di atas dapat digunakan untuk penundaan eksekusi di atas 10 siklus.

Pembentukan clock dengan frekuensi yang lebih rendah dapat dilakukan dengan listing penundaan menggunakan struktur perulangan berkalang atau menggunakan fasilitas pewaktu (timer). Sebuah pewaktu dapat menunda hingga 65 ribu siklus. Penggabungan antara pewaktu dengan struktur perulangan dapat menunda hingga 1 juta siklus dengan frekuensi keluaran $1 \mathrm{~Hz}$.

\section{Analisis Ketepatan Frekuensi Clock}

Pada Tabel 1 terlihat beberapa frekuensi yang dapat dikeluarkan dengan jumlah sisipan NOP yang dibutuhkan. Tidak semua frekuensi dapat dikeluarkan. Frekuensi keluaran $1 \mathrm{MHz}$ diperoleh dengan tidak adanya waktu tunda antara dua instruksi CPL yang berurutan. Sedangkan frekuensi keluaran $500 \mathrm{kHz}$ diperoleh dengan waktu tunda satu siklus. Frekuensi antara $1 \mathrm{MHz}$ dan $500 \mathrm{kHz}$ tidak dapat dibangkitkan karena tidak ada satu pun instruksi yang dapat disisipkan di antara dua instruksi CPL berurutan sehingga kedua instruksi CPL tersebut tertunda selama kurang dari satu siklus. Jika dikehendaki frekuensi keluaran antara $500 \mathrm{kHz}$ dan $1 \mathrm{MHz}$, maka frekuensi keluaran dapat dibulatkan ke 500 $\mathrm{kHz}$ atau $1 \mathrm{MHz}$. Agar menghasilkan galat terkecil, frekuensi di atas $749,9 \mathrm{kHz}$ dibulatkan ke $1 \mathrm{MHz}$ dan di bawah nilai tersebut dibulatkan ke 500 kHz sebagaimana Gambar 3. 


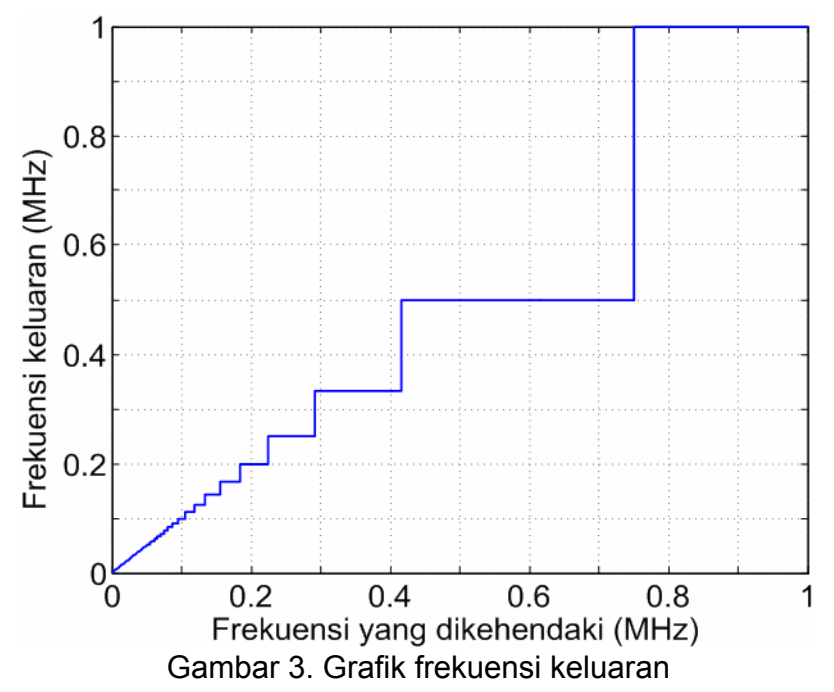

Galat untuk frekuensi $749,9 \mathrm{kHz}$ adalah

$$
\begin{aligned}
\text { Galat } & =\frac{|749,9 \mathrm{kHz}-1 \mathrm{MHz}|}{749,9 \mathrm{kHz}} \\
& =33,3 \%
\end{aligned}
$$

Galat tersebut merupakan galat tertinggi yang dapat terjadi. Galat untuk frekuensi yang lain dapat dilihat pada grafik di Gambar 4. Frekuensi yang tercantum pada Tabel 1 mempunyai galat $0 \%$. Semakin tinggi frekuensi keluaran, semakin tinggi pula galat yang terjadi. Pembangkit frekuensi analog biasanya mempunyai galat maksimal 5\%, dan pembangkit frekuensi digital biasanya mempunyai galat maksimal $0,1 \%$.

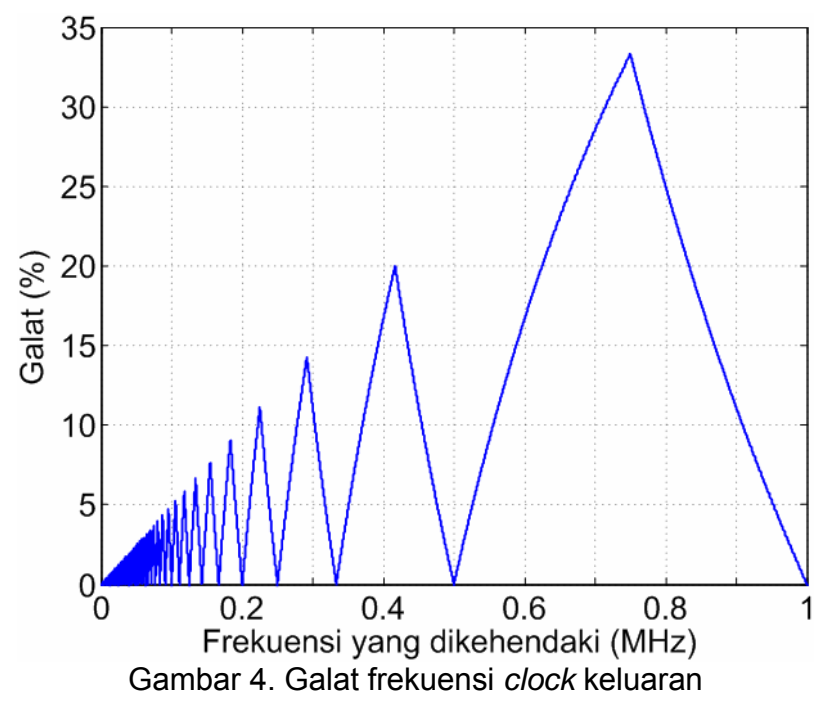

Dengan clock $24 \mathrm{MHz}$, mikrokontroler ini dapat mengeluarkan frekuensi dari $1 \mathrm{~Hz}$ hingga $1 \mathrm{kHz}$ dengan galat kurang dari $0,05 \%$, sebagaimana terlihat pada Gambar 5. Sehingga pada kisaran tersebut dapat digunakan ketepatan frekuensi keluaran hingga tiga digit. Pada kisaran tersebut, semua frekuensi dapat dikeluarkan dengan galat kurang dari 0,05\%.

Pada kisaran dari 1 hingga $2 \mathrm{kHz}$, galat maksimal yang terjadi masih di bawah 0,1\%. Sehingga pada kisaran ini pun dapat digunakan ketepatan frekuensi keluaran hingga tiga digit, misalnya $1010 \mathrm{~Hz}, 1020 \mathrm{~Hz}$ dan $1030 \mathrm{~Hz}$. Penggunaan frekuensi keluaran dengan ketepatan melebihi tiga digit dapat memberikan hasil salah jika diukur dengan pencacah frekuensi (Frequency Counter).

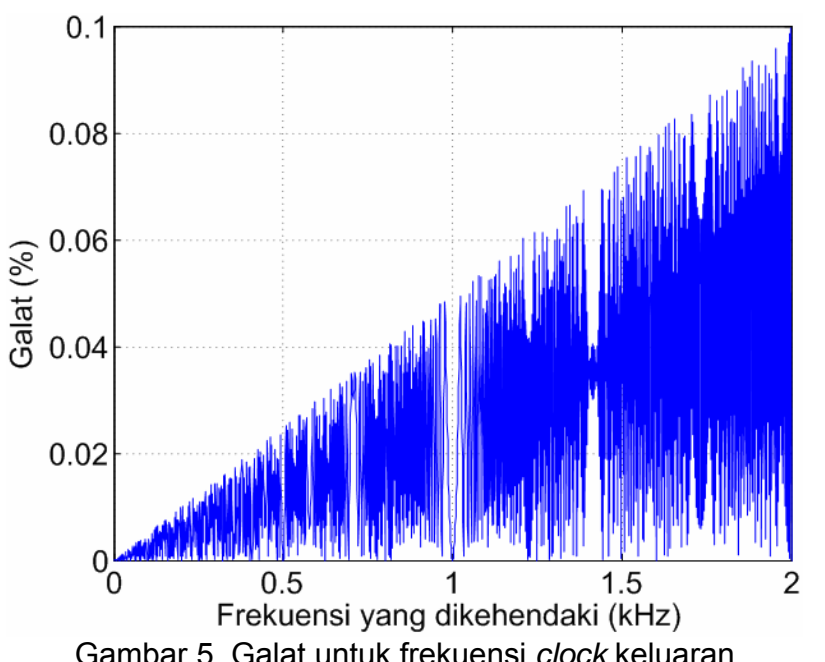

Gambar 5. Galat untuk frekuensi clock keluaran $1 \mathrm{~Hz} \sim 2 \mathrm{kHz}$.

Sebagai contoh, jika digunakan ketepatan empat digit, maka terdapat beberapa frekuensi yang tidak dapat dikeluarkan. Frekuensi terendah yang tidak dapat dikeluarakan adalah $1023 \mathrm{~Hz}$. Frekuensi terdekat yang akan dikeluarkan adalah 1022,49 Hz. Pada pencacah frekuensi, frekuensi tersebut dapat terdeteksi sebagai $1022 \mathrm{~Hz}$ (galat 0,049\%) atau $1023 \mathrm{~Hz}$ (galat 0,053\%).

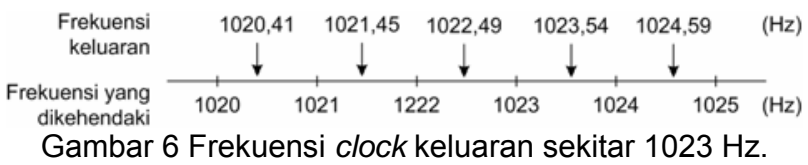

Di atas $1023 \mathrm{~Hz}$, terdapat semakin banyak frekuensi yang tidak dapat dikeluarkan. Beberapa frekuensi pun mempunyai galat mendekati $0,1 \%$. Untuk itu akan lebih bijak jika di atas $1 \mathrm{kHz}$, ketelitian frekuensi keluaran dibatasi tiga digit saja. Dengan pembatasan ketepatan tiga digit, semua frekuensi dari $1 \mathrm{kHz}$ hingga $2 \mathrm{kHz}$ dapat dikeluarkan. 
Pada kisaran frekuensi keluaran $2 \mathrm{kHz}$ ke atas, galat frekuensi keluaran dapat melebihi $0,1 \%$. Frekuensi keluaran terendah dengan galat melebihi $0,1 \%$ adalah $2064 \mathrm{~Hz}$. Jika mikrokontroler ini dikehendaki untuk mengeluarkan frekuensi tersebut, maka frekuensi keluaran terdekat yang akan dibangkitkan adalah 2066,1 Hz dengan galat $0,103 \%$.

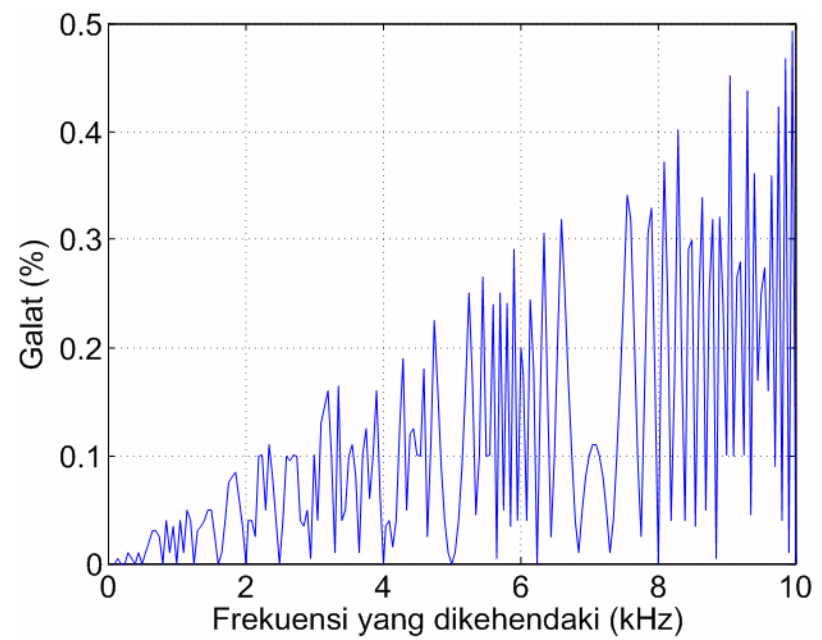

Gambar 7. Galat untuk frekuensi clock keluaran $1 \mathrm{~Hz} \sim 10 \mathrm{kHz}$.

Pada kisaran frekuensi di bawah $10 \mathrm{kHz}$, galat yang terjadi masih di bawah $0,5 \%$. Sehingga pada kisaran frekuensi dari $2 \mathrm{kHz}$ hingga $10 \mathrm{kHz}$ dapat diterapkan ketepatan 2,5 digit. Pada kisaran tersebut, semua nilai frekuensi dengan ketepatan hingga 2,5 digit dapat dikeluarkan. Galat terbesar untuk kisaran ini adalah $0,49 \%$ dan terjadi pada frekuensi $9.950 \mathrm{~Hz}$.

Pada kisaran frekuensi keluaran $10 \mathrm{kHz}$ hingga $20 \mathrm{kHz}$ dapat terjadi galat hingga mendekati $1 \%$. Sehingga pada kisaran ini sebaiknya digunakan ketepatan 2 digit. Galat terbesar untuk kisaran ini adalah 0,79\%. Ini terjadi pada frekuensi yang dikehendaki 18 $\mathrm{kHz}$ dengan frekuensi keluaran $17,86 \mathrm{kHz}$.

Tabel 2. Galat maksimal dan digit ketepatan

\begin{tabular}{|c|c|c|c|}
\hline $\begin{array}{c}\text { Kisaran } \\
\text { Frekuensi } \\
(\mathrm{Hz})\end{array}$ & $\begin{array}{c}\text { Galat } \\
\text { maksimal }\end{array}$ & $\begin{array}{c}\text { Digit } \\
\text { Ketepatan }\end{array}$ & $\begin{array}{c}\text { Dapat } \\
\text { dikeluarkan }\end{array}$ \\
\hline $1 \sim 1 \mathrm{k}$ & $0,05 \%$ & 3 & $\begin{array}{c}\text { Semua } \\
\text { frekuensi }\end{array}$ \\
\hline $1 \mathrm{k} \sim 2 \mathrm{k}$ & $0,1 \%$ & 3 & $\begin{array}{c}\text { Semua } \\
\text { frekuensi }\end{array}$ \\
\hline $2 \mathrm{k} \sim 10 \mathrm{k}$ & $0,5 \%$ & 2,5 & $\begin{array}{c}\text { Semua } \\
\text { frekuensi }\end{array}$ \\
\hline $10 \mathrm{k} \sim 20 \mathrm{k}$ & $1 \%$ & 2 & $\begin{array}{c}\text { Semua } \\
\text { frekuensi }\end{array}$ \\
\hline $20 \mathrm{k} \sim 40 \mathrm{k}$ & $1 \%$ & 2 & $\begin{array}{c}\text { Frekuensi } \\
\text { tertentu }\end{array}$ \\
\hline
\end{tabular}

Galat yang terjadi pada frekuensi di atas $20 \mathrm{kHz}$ hingga $40 \mathrm{kHz}$ cukup bervariasi. Dengan membatasi galat maksimal $1,5 \%$, masih dapat diperoleh frekuensi keluaran dengan ketepatan 1,5 digit. Galat terbesar di kisaran ini yaitu 1,48\% dan terjadi pada frekuensi $35 \mathrm{kHz}$ yang menghasilkan frekuensi $35,48 \mathrm{kHz}$. Namun, tidak layak jika keluaran generator frekuensi menggunakan ketepatan 1,5 digit. Akan lebih baik jika tetap digunakan ketepatan 2 digit, tapi hanya frekuensi tertentu yang dapat dikeluarkan. Frekuensi yang dapat dikeluarkan hanyalah yang mempunyai galat di bawah $1 \%$.

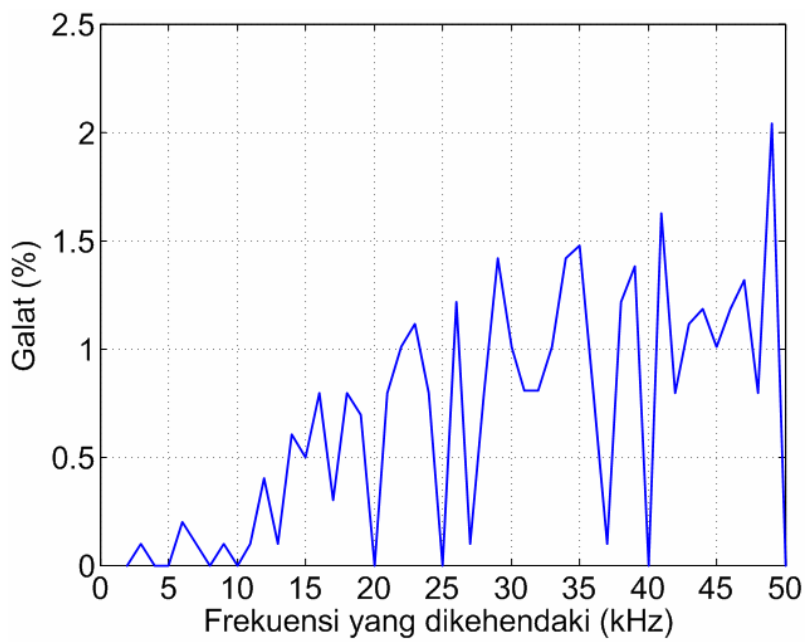

Gambar 8. Galat untuk frekuensi hingga $50 \mathrm{kHz}$.

Jika galat dipertahankan di bawah $1 \%$, semakin tinggi kisaran frekuensi maka semakin sedikit nilai frekuensi yang dapat dikeluarkan. Pada kisaran $20 \mathrm{kHz}$ hingga 100 $\mathrm{kHz}$, frekuensi yang dapat dikeluarkan dapat dilihat pada Tabel 3. Untuk frekuensi keluaran $100 \mathrm{kHz}$ ke atas hanya ada 10 nilai frekuensi yang dapat dikeluarkan, yaitu $1 \mathrm{MHz}$ dan sembilan nilai frekuensi yang ada pada Tabel 1.

Jika dikehendaki akan dikeluarkan suatu frekuensi acak, maka terdapat kemungkinan frekuensi tersebut tidak dapat dikeluarkan. Semakin tinggi frekuensi keluaran, maka semakin tinggi pula kemungkinan frekuensi tersebut tidak dapat dikeluarkan atau semakin kecil kemungkinan frekuensi tersebut dapat dikeluarkan.

Kemungkinan suatu frekuensi acak di bawah $1 \mathrm{kHz}$ dapat dikeluarkan adalah 1 karena semua frekuensi di bawah $1 \mathrm{kHz}$ dapat dikeluarkan. Grafik kemungkinan suatu frekuensi acak dapat dikeluarkan (Pf) untuk kisaran $1 \mathrm{kHz}$ hingga $1 \mathrm{MHz}$ dapat dilihat pada Gambar 9. 
Tabel 3. Frekuensi keluaran dengan galat di bawah $1 \%$ pada kisaran $20 \mathrm{kHz}$ hingga $100 \mathrm{kHz}$.

\begin{tabular}{|c|c|c|c|}
\hline $\begin{array}{l}\text { Kisaran } \\
\text { frekuensi } \\
(\mathrm{kHz})\end{array}$ & $\begin{array}{c}\text { Frekuensi } \\
\text { yang dapat } \\
\text { dikehendaki } \\
(k H z)\end{array}$ & $\begin{array}{c}\text { Frekuensi } \\
\text { keluaran } \\
(\mathrm{kHz})\end{array}$ & $\begin{array}{c}\text { Galat } \\
(\%)\end{array}$ \\
\hline \multirow[t]{5}{*}{$20<f \leq 30$} & 21 & 20,83 & 0,79 \\
\hline & 24 & 23,81 & 0,79 \\
\hline & 25 & 25,00 & 0,00 \\
\hline & 27 & 27,03 & 0,10 \\
\hline & 28 & 27,78 & 0,79 \\
\hline \multirow[t]{5}{*}{$30<f \leq 40$} & 31 & 31,25 & 0,81 \\
\hline & 32 & 32,26 & 0,81 \\
\hline & 36 & 35,71 & 0,79 \\
\hline & 37 & 37,04 & 0,10 \\
\hline & 40 & 40,00 & 0,00 \\
\hline \multirow[t]{3}{*}{$40<f \leq 50$} & 42 & 41,67 & 0,79 \\
\hline & 48 & 47,62 & 0,79 \\
\hline & 50 & 50,00 & 0,00 \\
\hline \multirow[t]{3}{*}{$50<f \leq 60$} & 53 & 52,63 & 0,70 \\
\hline & 56 & 55,56 & 0,79 \\
\hline & 59 & 58,82 & 0,30 \\
\hline \multirow{3}{*}{$60<f \leq 70$} & 62 & 62,50 & 0,81 \\
\hline & 63 & 62,50 & 0,79 \\
\hline & 67 & 66,67 & 0,50 \\
\hline \multirow[t]{3}{*}{$70<f \leq 80$} & 71 & 71,43 & 0,60 \\
\hline & 72 & 71,43 & 0,79 \\
\hline & 77 & 76,92 & 0,10 \\
\hline \multirow{2}{*}{$80<f \leq 90$} & 83 & 83,33 & 0,40 \\
\hline & 84 & 83,33 & 0,79 \\
\hline \multirow{2}{*}{$\begin{array}{c}90<f \leq \\
100\end{array}$} & 91 & 90,91 & 0,10 \\
\hline & 100 & 100,00 & 0,00 \\
\hline
\end{tabular}

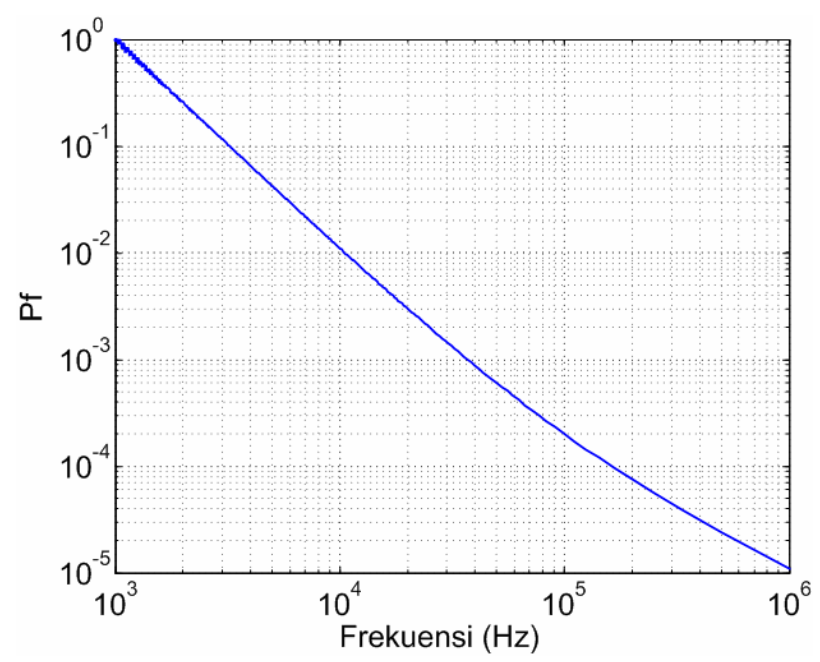

Gambar 9. Kemungkinan suatu frekuensi dapat dikeluarkan

\section{KESIMPULAN}

Dari analisis yang telah dikemukakan di muka dapat diambil beberapa simpulan sebagai berikut:

1. Mikrokontroler dapat digunakan sebagai pembangkit clock hingga frekuensi $2 \mathrm{kHz}$ dengan ketepatan 3 digit dan galat kurang dari $0,1 \%$.

2. Mikrokontroler ini masih layak pula digunakan sebagai pembangkit clock pada kisaran frekuensi audio yaitu hingga 20 $\mathrm{kHz}$ dengan ketepatan 2 digit dan galat maksimal $1 \%$.

3. Untuk kisaran $20 \mathrm{kHz}$ hingga $1 \mathrm{MHz}$, frekuensi keluaran dengan galat $1 \%$ masih dapat dikeluarkan namun untuk nilai-nilai tertentu.

\section{DAFTAR PUSTAKA}

Atmel Corporation. (1997). Microcontroller Instrusction Set, Atmel Corporation, San Jose, USA.

Atmel Corporation. (2007). Atmel 8051 Microcontrollers Hardware Manual, Atmel Corporation, San Jose, U.S.A.

The Controller Continuum Family. (2008). Microcontroller-Based Sine Wave Generator Has Crystal Accuracy, Penton Media Inc.

Tocci, R.J. dan Widmer, N.S. (1998). Digital Systems, $7^{\text {th }}$ edition, Prentice-Hall, Inc., New Jersey, U.S.A. 